\section{Scientist Spotlight Homework Assignments Shift Students' Stereotypes of Scientists and Enhance Science Identity in a Diverse Introductory Science Class}

\author{
Jeffrey N. Schinske, ${ }^{\dagger *}$ Heather Perkins, ${ }^{\ddagger}$ Amanda Snyder, ${ }^{\dagger}$ and Mary Wyer ${ }^{\ddagger}$ \\ 'Biology Department, De Anza College, Cupertino, CA 95014; 'Psychology Department, North \\ Carolina State University, Raleigh, NC 27695
}

\begin{abstract}
Research into science identity, stereotype threat, and possible selves suggests a lack of diverse representations of scientists could impede traditionally underserved students from persisting and succeeding in science. We evaluated a series of metacognitive homework assignments ("Scientist Spotlights") that featured counterstereotypical examples of scientists in an introductory biology class at a diverse community college. Scientist Spotlights additionally served as tools for content coverage, as scientists were selected to match topics covered each week. We analyzed beginning- and end-of-course essays completed by students during each of five courses with Scientist Spotlights and two courses with equivalent homework assignments that lacked connections to the stories of diverse scientists. Students completing Scientist Spotlights shifted toward counterstereotypical descriptions of scientists and conveyed an enhanced ability to personally relate to scientists following the intervention. Longitudinal data suggested these shifts were maintained 6 months after the completion of the course. Analyses further uncovered correlations between these shifts, interest in science, and course grades. As Scientist Spotlights require very little class time and complement existing curricula, they represent a promising tool for enhancing science identity, shifting stereotypes, and connecting content to issues of equity and diversity in a broad range of STEM classrooms.
\end{abstract}

\section{INTRODUCTION}

Whether or not we consciously register the impacts of this messaging, we are regularly bombarded with information regarding the types of people who work in science, technology, engineering, and mathematics (STEM). From television shows and movies to websites, news articles, and advertisements, the media recurrently conveys images of who does science, more often than not showcasing a relatively narrow view of science and scientists. Setting the media aside, perhaps we need look no further than our own classrooms to understand the ways scientists are portrayed. Many students are likely to get their earliest and most direct experiences with "real" scientists when attending college STEM classes_classes taught by a mostly white, mostly male faculty nationwide (National Science Foundation, 2013). Our textbooks, in the very rare instances they connect content to discussions of specific scientists, can tend to focus the most attention on individuals matching common scientist stereotypes (e.g., Darwin and Mendel in Reece et al., 2014). Even our classrooms themselves may, through their physical layouts and decorations, convey messages regarding who can participate in STEM (Cheryan et al., 2009). We might wonder, then, what are the impacts of these recurrent messages on students enrolled in postsecondary STEM classes, particularly in the increasingly diverse classroom environments of the United States? And what, if anything, might faculty do in response to this messaging?
Pat Marsteller, Monitoring Editor Submitted January 15, 2016; Revised June 11 2016; Accepted June 14, 2016

CBE Life Sci Educ September 1, 2016 15:ar47

DOI:10.1187/cbe.16-01-0002

*Address correspondence to: Jeffrey N. Schinske (schinskejeff@fhda.edu).

(c) 2016 J. N. Schinske et al. CBE-Life Sciences Education @ 2016 The American Society for Cell Biology. This article is distributed by The American Society for Cell Biology under license from the author(s). It is available to the public under an Attribution-Noncommercial-Share Alike 3.0 Unported Creative Commons License (http://creativecommons.org/licenses/ by-nc-sa/3.0).

"ASCB®" and "The American Society for Cell Biology $\circledR^{\prime \prime}$ are registered trademarks of The American Society for Cell Biology. 


\section{Scientist Stereotypes Impact Persistence and Success in STEM by Influencing Science Identity, Sense of Belonging, and Stereotype Threat}

The messages we convey to students, either intentionally or unintentionally, regarding who does science can influence students' stereotypes of scientists. Many lines of evidence point to the importance of these stereotypes in shaping students' sense of belonging in STEM, with implications for persistence and success in STEM programs. For example, stereotypical representations of scientists in the media (Tanner, 2009; Cheryan et al., 2013; DeWitt et al., 2013; Martin, 2015) and in classroom decorations (Cheryan et al., 2009) have the potential to reduce interest in STEM fields among women and people of color. On the other hand, a variety of studies suggest students are more likely to pursue majors and careers in STEM if they agree with certain "positive" stereotypes of scientists (Beardslee and O’Dowd, 1961; Wyer, 2003; Schneider, 2010). Our own work further suggests that holding counterstereotypical images of scientists might be an important factor in predicting success in science classes (Schinske et al., 2015).

These findings illustrate the importance of science identity, a sense of belonging, and stereotype threat in determining persistence and success in STEM classes. Identity refers to the extent to which we view ourselves as a particular "kind of person" (Gee, 2000), with science identity more specifically referring to whether we see ourselves as scientists. If students hold stereotypes that portray scientists as a different "kind of person" than themselves, those students might conclude they are not "science people." This mismatch between a student's personal sense of identity and a science identity can hamper persistence in STEM (Seymour and Hewitt, 1997; Brickhouse et al., 2000). Harboring views of scientists that differ from students' perceptions of themselves could also cause students to feel as though they do not belong in science. The extent to which students feel a sense of belonging similarly correlates with levels of achievement and motivation in school settings (Goodenow, 1993; Roeser et al., 1996).

Feeling that one differs from stereotypical descriptions of people in a particular field of study can additionally hinder achievement in that field due to stereotype threat. Under stereotype threat, students harbor an often subconscious fear of confirming a negative stereotype about their groups (Steele, 1997). For example, students of color, women, and first-generation college students might fear confirming a stereotype that their groups are not good at science due to a perception that scientists are white men from privileged, highly educated backgrounds. This threat can undermine engagement and performance, even among students who are otherwise well qualified academically (Steele, 1997). Even subtle cues involving a lack of women or people of color visually represented in an academic environment or on a flyer can trigger dramatic reductions in interest and performance due to stereotype threat (Inzlicht and Ben-Zeev, 2000; Purdie-Vaughns et al., 2008). More specific to science contexts, stereotype threat has been described as a significant factor in predicting interest, persistence, and success in STEM majors, especially for women and students of color (Hill et al., 2010, chap. 3; Beasley and Fischer, 2012). Interventions that remove the conditions that trigger stereotype threat can reduce or even entirely eliminate achievement gaps between women and men or between stu- dents of color and white students in test scores and course grades (e.g., Steele and Aronson, 1995; Good et al., 2003; Cohen et al., 2006).

\section{What Can Faculty Do in STEM Classes to Broaden the Image of the Scientist?}

Given the evidence suggesting that stereotypes of scientists impact persistence and success in STEM, efforts to feature counterstereotypical images of scientists have the potential to narrow equity gaps and broaden participation in STEM. Stereotypes of scientists are malleable (Cheryan et al., 2015), and previous work suggests that providing counterstereotypical messaging could enhance interest and success in STEM among underserved populations of students (McIntyre et al., 2004; Steinke et al., 2009; Cheryan et al., 2013).

One common strategy for introducing counterstereotypical images of scientists to students is to increase the prevalence and visibility of diverse STEM "role models"-individuals who students may choose to emulate. Marx and Roman (2002) describe how role models are chosen through "selective, social comparison whereby certain attributes are copied and others are excluded." Because comparisons of social similarity may involve the visible personal characteristics of potential role models, many studies have focused on the potential benefits of genderor race/ethnic-matched role models. For example, the presence of female role models has served to mitigate stereotype threat and boost math performance among female students (Marx and Roman, 2002; Marx and Ko, 2012). In terms of race/ethnicity, both white and nonwhite students tend to select race/ ethnic-matched career role models (Karunanayake and Nauta, 2004), and having a race/ethnic-matched instructor role model has been shown to correlate with student success (Dee, 2004; Fairlie et al., 2011).

While these results would suggest placing a priority on seeking out gender/race/ethnic-matched role models for STEM students, other studies have failed to find distinct benefits of role models who match students' own races/ethnicities and genders (Ehrenberg et al., 1995; Maylor, 2009; Phelan, 2010). Perhaps explaining these discrepancies, Marx and Roman (2002) point out that the attributes important to seek in a role model will ultimately be those attributes of importance to the individual choosing the role model (e.g., the attributes considered important by students). Because social identities are informed by many different factors, and individuals have multiple identities that resonate in different contexts (Gee, 2000), it might be difficult to predict which role model attributes will be most important in encouraging students to form a science identity. Buck et al. (2008) provide guidance in this area in finding that students needed to identify someone "who cared about them and shared common interest/ experiences" in order for role models to be effective. This work implies that faculty interested in enhancing students' science identity and sense of belonging in STEM should, in addition to identifying diverse role models in terms of gender/race/ethnicity, place a priority on featuring individuals to whom students might personally relate, based on interests and experiences.

\section{Moving from Identifying Role Models to Showcasing Possible Selves}

The concept of "possible selves" might represent a more useful and precise way to think of counterstereotypical examples than 
does the concept of "role modeling." Possible selves refer to everything that each of us "is tempted to call by the name of $m e$ " (James, 2005) or the set of "individually significant hopes, fears, and fantasies" that define oneself (Markus and Nurius, 1986). Individuals can reflect upon their own possible selves, and these possible selves are understood to influence motivation and future behavior (Markus and Nurius, 1986). Students weigh their possible selves in constructing school identities, and these interactions between possible selves and academic identities mediate the potency of stereotype threat (Steele, 1997; Oyserman et al., 2006). Possible selves more specifically play an important role in the development of a science identity (Hunter, 2010), and students' "possible science selves" might help explain career choices in STEM (Steinke et al., 2009; Mills, 2014). Taken together, this implies students' science identities and resistance to stereotype threat might be enhanced if they see their own their own possible selves reflected in STEM. This highlights a subtle but important difference between the concepts of role models and possible selves. Compared with featuring scientist role models that represent people students are expected to become more like, seeing one's possible self in a scientist would involve seeing someone in science you already are like.

\section{Goals and Scope of This Study}

Given the evidence that counterstereotypical perceptions of scientists are important in diverse science classrooms (Schinske et al., 2015) and that viewing one's possible selves in science might enhance science identity (Hunter, 2010; Mills, 2014) and mitigate stereotype threat (Oyserman et al., 2006), we developed and evaluated a classroom intervention to introduce students to counterstereotypical examples of scientists. In evaluating the intervention, which we call "Scientist Spotlights" (see Methods), we sought to explore the following four hypotheses.

Hypothesis 1: Scientist Spotlights will shift students' descriptions of scientists toward nonstereotypical descriptions.

Hypothesis 2: Scientist Spotlights will enhance students' ability to see their possible selves in science by enhancing their ability to relate to scientists.

Hypothesis 3: Shifts in scientist stereotypes and relatability of scientists will correlate with students' interest in science.

Hypothesis 4: Shifts in scientist stereotypes and relatability of scientists will correlate with course grades.

\section{METHODS}

Below we review the development of the Scientist Spotlight intervention, the study context, and our mixed-methods analysis of student essays and quantitative surveys to evaluate the intervention.

\section{Development of Scientist Spotlights in a Diverse Community College Biology Classroom}

We developed Scientist Spotlights as regular, out-of-class assignments both to introduce counterstereotypical examples of scientists and to assist in the coverage of course content while requiring little class/grading time. Featured scientists were selected to 1) present diverse perspectives on who scientists are and how science is done and 2) match the content areas being covered at the time of each assignment. In each Scientist
Spotlight, students reviewed a resource regarding the scientist's research (e.g., a journal article or popular science article) and a resource regarding the scientist's personal history (e.g., an interview, Story Collider podcast, or TED Talk). Because these assignments included the review of materials that introduced course content to students, they replaced weekly textbook readings. One of the Scientist Spotlights assigned to students read as follows:

Ben Barres is a Stanford professor of neurobiology. He studies diseases related to signaling in the nervous system, and in particular the roles of supporting cells around neurons. Dr. Barres is also a leader in science equity and the effort to address gender gaps. He is uniquely positioned to address these issues, since he has presented both as a female and a male scientist at different times in his career.

1. View the Wall Street Journal article about Ben Barres by clicking here (Begley, 2006).

2. Then, review Dr. Barres' article in the journal Nature by clicking here (Allen and Barres, 2009)

(If you are interested in hearing more from Ben Barres, you can search for him on YouTube. He has some videos on his research and also on his experiences as a transgender person.)

After reviewing these resources, write a 350 word or more reflection with your responses to what you saw. You might wish to discuss:

1. What was most interesting or most confusing about the articles you read about Dr. Barres?

2. What can you learn about neuron signaling (action potentials, synapses, supporting cells) from these articles?

3. What do these articles tell you about the types of people that do science?

4. What new questions do you have after reviewing these articles?

The above example was assigned before a unit on neuron signaling and therefore assisted in the introduction of content in that area. The writing prompts were aimed at creating opportunities for metacognition (Tanner, 2012). Prompts changed slightly from one assignment to the next, but the third prompt about the "types of people that do science" was always included. A photograph of the featured scientist was also included with each assignment. Students submitted responses to Scientist Spotlights through an online course-management system (Moodle), and submissions were scored only for timeliness and word count.

\section{Study Design}

We used a quasi-experimental, nonequivalent-groups design (Shadish et al., 2002; Trochim, 2006) to evaluate Scientist Spotlights in a Human Biology course at a diverse community college during the Fall 2013-Fall 2015 academic terms. Human Biology is a one-quarter lecture/lab general education course open to any student, but targeting transfer students and those with interests in human health careers. Students in five sections of Human Biology during that time period completed Scientist Spotlights on a weekly basis (hereafter "Scientist Spotlight 
Homework" students). Each Scientist Spotlight was worth 10 points, so the assignments $(n=10)$ contributed a total of 100 points to the final course grade (865 points in the whole course). Efforts were made to attend to multiple axes of diversity when selecting scientists to feature, with special attention to the racial/ethnic diversity of students in these classes. Half of the weeks featured female scientists and seven out of 10 weeks featured at least one nonwhite scientist. Occasionally, more than one scientist was featured during a Scientist Spotlight assignment. Selected scientists represented diverse socioeconomic backgrounds, gender identities, interests outside science, paths to careers in science, temperaments, ages, sexual orientations, and countries of origin. Supplemental Material, part A, lists the names of individuals featured in Scientist Spotlights during this study. The full set of 10 Scientist Spotlight assignments, including readings and resources, is available by request to the corresponding author.

During the same time period, students in two sections of Human Biology did not perform Scientist Spotlights. Instead, those students completed comparable metacognitive online assignments (example in Supplemental Material, part B) based on popular science articles and journal articles compiled in a course reader (hereafter "Course Reader Homework" students). Although no explicit instruction regarding scientist stereotypes took place in these classes, three scientists were briefly discussed during lecture presentations. An African-American female scientist (Jewel Plummer Cobb), a white male scientist (Neil Shubin), and a Japanese male scientist (Masayasu Kojima) were all mentioned during class while highlighting certain research findings related to course content. Students saw photographs of all three scientists and watched brief videos featuring Dr. Cobb and Dr. Shubin but did not perform any individual/group work or metacognitive activities surrounding these scientists.

Quasi-experimental approaches, by definition, lack randomization in assigning participants to groups (Shadish et al., 2002; Trochim, 2006). As such, students self-selected into Human Biology course sections and the instructor (J.N.S.) selected sections in which to implement Scientist Spotlight versus Course Reader Homework. While nonrandom assignment to groups can limit researchers' ability to infer causal connections between interventions and outcomes, quasi-experimental approaches can still provide robust and valuable insights and offer advantages over randomized experiments in certain contexts (Shadish et al., 2002). We attempted to ensure as much equivalence as possible between groups in that all classes adhered to the same curricular expectations, were taught at similar times of the day in similarly arranged classrooms, and used the same types of in-class activities. The same faculty member (J.N.S.) served as instructor for all of the course sections involved in this study, though one Course Reader Homework section was cotaught by another faculty member. We controlled for various student-level differences between groups during statistical analyses and used these "weighted means" in evaluating our hypotheses (see Methods and Supplemental Material, part E). It should be noted that, in the analyses that follow, we consider students as the experimental units. This was considered most appropriate in this instance, because Scientist Spotlights were designed to interact with individual students in different ways, raising interest in students as individual observations. We do, however, control for course section in analyses to account for trends based on grouping at the class level.

\section{Student Population}

This work was conducted at a large ( 22,000 students) California community college that is a designated Asian American and Native American Pacific Islander-Serving Institution (AANAPISI). The majority (59\%) of students come from low-socioeconomic status (low-SES) families and the majority (66.2\%) indicate the educational goal of transferring to a 4-year institution. Approximately $20 \%$ of Human Biology students state the intention of majoring in biology. Forty-six percent of students report that Human Biology is the first college science class they have taken, and $13 \%$ of students report that Human Biology is the first science class they have ever taken at any level.

A total of 364 students initially enrolled in the five sections of Human Biology that completed Scientist Spotlight Homework ( $\bar{x}=73$ students per class). One hundred thirty-nine students initially enrolled in the Course Reader Homework sections ( $\bar{x}=70$ students per class). However, 26 students from Scientist Spotlight Homework classes and 13 students from Course Reader Homework classes dropped the course within the first 2 weeks of class, leaving 338 students as the final enrollment for Scientist Spotlight Homework sections and 126 students in Course Reader Homework sections.

The table in the Supplemental Material, part C, compares the demographic characteristics of students in these classes. We defined "underserved" racial/ethnic groups as those groups that have persistently entered STEM majors at lower rates compared with their prevalence on campus and experienced comparatively lower success rates in STEM classes. This included students identifying as Latino/a, Black, Native American, Filipino/a, Pacific Islander, and Southeast Asian (e.g., Vietnamese, Laotian, Cambodian, Indonesian). The majority of Scientist Spotlight and Course Reader Homework students identify as members of underserved groups (Supplemental Material, part C). Students in these Human Biology classes identified 25 different first languages spoken, with English, Spanish, and Vietnamese representing the most common first languages spoken.

\section{Assessment of Scientist Stereotypes and Possible Science Selves through Short-Essay Surveys}

In evaluating Scientist Spotlights, we used a mixed-methods approach in which we reviewed short-essay responses from students for context and themes and then coded student responses into categories for quantitative analysis. Two essay prompts were used. The first prompt was designed to address hypothesis 1 by eliciting students' stereotypes of scientists. This prompt read, "Based on what you know now, describe the types of people that do science. If possible, refer to specific scientists and what they tell you about the types of people that do science" (hereafter "stereotypes prompt"). This prompt was described and its validity was explored by Schinske et al. (2015). The second prompt was developed as an exploratory method for assessing students' possible selves in science. That is, assessing whether students perceived scientists as reflecting their possible selves, and if so, what aspects of themselves they saw reflected in scientists (hypothesis 2). We chose to approach this topic by surveying the extent to which students could 
"personally relate" to scientists. The prompt consisted of the challenge statement: "I know of one or more important scientist to whom I can personally relate," followed by a Likert scale including "agree," "somewhat agree," "somewhat disagree," "disagree," and "I don't know." Following the Likert scale, students were instructed: "Please explain your opinion of the statement" (hereafter "relatability prompt"). This prompt was developed and face validity was established through multiple quarters of testing in class and informal talk-aloud trials with students. Even though an "I don't know" response was essentially the same as "disagree" when students responded whether they knew of one or more relatable scientists (see also Results), we found it important to include an "I don't know" option. Some students were more comfortable circling "I don't know" than "disagree," which sounded like a "wrong" answer to them.

These two prompts were printed on one side of a sheet of paper, so students had approximately half a sheet to respond to each prompt. J.N.S. provided the surveys to students on the first and last days of each Human Biology course, telling students, "I am very interested in students' ideas about science and scientists, so I appreciate you taking 5-10 min to respond to these prompts. There are absolutely no right or wrong answers and there's nothing I would like more than to see many different thoughts on the topic. Your responses will not be graded and will not be reviewed in connection with your name." Though responses were not graded, students received five points (out of 865 course points) for participating and completing surveys. When looking for shifts in attitudes about scientists in these surveys, only papers from students who submitted both beginning- and end-of-course responses were considered. As preliminary results suggested students in Scientist Spotlight Homework classes were adopting new attitudes regarding scientist stereotypes and the relatability of scientists, we were interested in whether those shifts would be maintained over time. To assess these shifts longitudinally, J.N.S. sent an online survey that included the stereotypes and relatability prompts to Scientist Spotlight Homework students approximately 6 months after the end of class.

\section{Analysis of Students' Descriptions of Scientists}

We anonymized and randomized student papers and followed the procedures of Schinske et al. (2015) to categorize responses to the stereotypes prompt. While reviewing student responses, we recorded the words, phrases, and names students used to describe scientists, and tallied the frequencies of those descriptions among the papers. Exemplar quotes were selected to represent the most common themes and provide context. Pseudonyms were used in place of student names to protect anonymity. Students' descriptions of scientists were then coded as Stereotypes, Nonstereotypes, or Fields of Science. Following our previous work (Schinske et al., 2015), we defined Stereotypes as any widely represented descriptions of scientists matching stereotypes uncovered by Mead and Metraux (1957). Nonstereotypes included less commonly used descriptions of scientists not reported in that previous work. Fields of Science included names of science fields or career types (e.g., biologist). We previously demonstrated that independent reviewers reliably code descriptions as Stereotypes (0.86 interrater correlation) and Nonstereotypes (0.89 interrater correlation; Schinske et al., 2015). We recorded the number of descriptions from each category for each student, then converted those numbers into percentages out of total comments (e.g., percent of Stereotypes out of all comments) to partly control for differences in the lengths of responses between students.

Changes in the proportions of Stereotypes and Nonstereotypes were analyzed using repeated-measure analysis of covariance (RM-ANCOVA). Proportions of Stereotypes/Nonstereotypes acted as dependent variables, with time (beginning vs. end of course) and treatment (Scientist Spotlight Homework vs. Course Reader Homework) input as between-subjects factors. Gender, race/ethnicity (categorized as traditionally underserved vs. traditionally well served), and course section were used as covariates.

\section{Analysis of Students' Ability to Personally Relate to Scientists}

We reviewed short-essay responses to the relatability prompt and transcribed each of students' statements (e.g., "Don't know any scientists," "Relate to musician scientist," "Relate to Rosalind Franklin") into the top of a spreadsheet. As those statements reappeared in subsequent papers, we tallied the appearance of the statements in the spreadsheet. Exemplar quotes were selected to represent the most common themes and provide context for why students could or could not personally relate to scientists.

Changes in students' relatability Likert-scale selections from the beginning to the end of the course, were analyzed using RM-ANCOVAs. Relatability Likert scores acted as the dependent variables, with time and treatment input as between-subjects factors. Gender, race/ethnicity, and course section were used as covariates.

\section{Analysis of Student Interest in Science and Collection of Demographic Information}

The exploration of hypothesis 3 required comparing shifts in students' stereotypes of scientists and ability to relate to scientists to shifts in science interest. To monitor student interest, during the first and the last weeks of class, students completed an online survey (Supplemental Material, part D). The survey included eight quantitative items adapted from the Student Assessment of their Learning Gains Survey (Seymour et al., 2000), which were reshaped into the "Science Interest" scale. Students responded to prompts such as "Presently I am enthusiastic about this subject" on a five-point Likert scale, ranging from "not at all" to "a great deal." Supplemental Material, parts $\mathrm{G}$ and $\mathrm{H}$, provide details regarding how the Science Interest scale was derived from these items. In separate questions, students indicated whether they were majoring in biology or another STEM field and whether they had taken previous science classes (Supplemental Material, part D). As we also wished to look for interactions involving student demographics, the final page of the surveys asked students to identify their gender and racial/ethnic identities and first spoken language. Students received five participation points (out of 865 course points) for completing these quantitative surveys.

Prior work suggested broader student outcomes, like grades and interest in science, relate to holding nonstereotypical views of scientists (Schinske et al., 2015) and developing possible science selves (Steinke et al., 2009; Mills, 2014). We therefore created categorical variables to distinguish students 
who exhibited these characteristics. Specifically, we compared end-of-course with beginning-of-course values to categorize students as either decreasing versus not decreasing in their proportion of Stereotypes, increasing versus not increasing in their proportion of Nonstereotypes, and increasing versus not increasing in relatability. The relationships between each of these categorical variables and Science Interest were tested in a $2 \times 2 \times 2$ (categorical variable $\times$ stereotype change $\times$ time) RM-ANCOVA controlling for gender, race/ethnicity, course section, and past science class experience.

\section{Analysis of Student Grades}

Students' course grades, expressed numerically ("A" = 4, "B" = 3 , etc.), were included in analyses to explore correlations between Stereotypes, Nonstereotypes, relatability, and in-class achievement. As in tests for correlations involving interest in science, we used the categorical variables we generated for changes in Stereotypes, Nonstereotypes, and relatability in ANCOVAs to explore connections between those variables and course grades. These analyses controlled for gender, race/ethnicity, course section, and past science class experience.

All statistical analyses were performed in SPSS (SPSS for Windows, 19.0.0, IBM, Armonk, NY). To enhance clarity and readability, we present descriptive statistics and ANCOVA tables from our analyses in the Supplemental Material, parts E and $\mathrm{F}$, rather than in the body of the article.

\section{RESULTS}

Hypothesis 1 Results: Scientist Spotlights Will Shift Students' Descriptions of Scientists toward Nonstereotypes Students' weekly Scientist Spotlight responses suggested the assignments encouraged students to reflect on counterstereotypical examples of scientists while engaging with course content. Fernanda commented on her previous stereotypical ideas about scientists and discussed how Charles Limb counteracted those stereotypes by showing an interest in music and a life outside of science could contribute to a scientific career:

I was able to see scientists in a different perspective ... I used to think scientists were mere geniuses who asked infinite, even unpredictable questions nobody had the time to research. I used to even think they were mere robots who ate, researched, and slept on a daily basis. Yet, they have a life of their own ... I can tell Dr. Limb is a good musician whose love for the music stretched to his eagerness to learn about the brain.-Fernanda, a Latina student responding to the Scientist Spotlight on Charles Limb

Melissa noted that Raymond Dubois's "humble beginnings" in an economically disadvantaged farming community represented a nontraditional path to science:

Dr. Dubois is such a unique person. He was born and raised to be a farmer, and didn't have very much money or aspiration ... He found science completely by accident and fell in love, and from such humble beginnings he became one of the country's foremost experts in his field. It's very impressive to see someone come from so traditionally unlikely a background and become so well-known for his work.--Melissa, a white female student responding to the Scientist Spotlight on Raymond Dubois
Shifts toward counterstereotypical views of scientists were also apparent in beginning- and end-of-course surveys. Two hundred forty-five Scientist Spotlight Homework students and 84 Course Reader Homework students submitted both beginning- and end-of-course responses to the stereotypes prompt. This prompt stated, "Based on what you know now, describe the types of people that do science. If possible, refer to specific scientists and what they tell you about the types of people that do science." Table 1 shows the most prevalent themes found in students' responses at the beginning and end of the course for both Scientist Spotlight Homework and Course Reader Homework sections. Beginning-of-course responses consisted mostly of "positive" stereotypes of scientists (Mead and Metraux, 1957). For example, Cynthia and Theresa voiced the common beginning-of-course opinion that scientists are highly intelligent/knowledgeable individuals:

People who are ... very intelligent and can think outside the box [do science].-Cynthia, a white female Scientist Spotlight Homework student

Intelligent people also do science. People [who] are good at science and excel in math tend to be scientists, like Albert Einstein.-CTheresa, a white female Course Reader Homework student

Matthew described scientists as innately curious:

I believe the types of people that do science are curious and doubtful. Scientists are innately curious and they question everything.-Matthew, a Vietnamese male Scientist Spotlight Homework student

Mei added a love of science as a possible inherent characteristic of scientists:

[Scientists] love science, at least the aspects that they work on ... They know a lot in their field but they are still eager to learn more.-Mei, a Chinese female Course Reader Homework student

It appears that, at the beginning of the course, students largely identified scientists as having stereotypical, innate qualities, such as intelligence, proficiency in math, curiosity, and interest in their fields of study. Pamela similarly commented on scientists' intelligence but also described one of the most common noninnate characteristics of scientists from the beginning of class. That is, scientists are people who do experiments or apply the scientific method:

[Scientists are] smart people that are crazy/confused. [They] study/research specific topics over long periods of time ... create experiments and do labs.--Pamela, a Black/Latina Scientist Spotlight Homework student

The stereotypes prompt asked students to name specific scientists to illustrate the types of people who do science. However, many students explicitly expressed a lack of familiarity with specific scientists at the beginning of the course. Albert Einstein was the most common specific scientist discussed by 
TABLE 1. Most common student descriptions of scientists from Scientist Spotlight Homework (A) and Course Reader Homework (B) students at the beginning and end of the course

\begin{tabular}{|c|c|c|c|}
\hline \multicolumn{4}{|l|}{ A. } \\
\hline \multicolumn{2}{|c|}{ Beginning of Scientist Spotlight courses } & \multicolumn{2}{|c|}{ End of Scientist Spotlight courses } \\
\hline Most common descriptions of scientists & Prevalence & Most common descriptions of scientists & Prevalence \\
\hline People that do experiments (s) & $24 \%$ & All types of people (n) & $49 \%$ \\
\hline Curious (s) & $20 \%$ & Passionate (s) & $24 \%$ \\
\hline Biologists (f) & $18 \%$ & Cheerleaders (n) & $22 \%$ \\
\hline Especially intelligent (s) & $17 \%$ & Darlene Cavalier (n) & $18 \%$ \\
\hline Albert Einstein (s) & $17 \%$ & People that do experiments (s) & $17 \%$ \\
\hline Doctors (f) & $15 \%$ & People from outside the United States (n) & $16 \%$ \\
\hline People that look for "truths" (s) & $13 \%$ & Curious (s) & $15 \%$ \\
\hline Chemists (f) & $13 \%$ & Creative (s) & $13 \%$ \\
\hline Discover things (s) & $12 \%$ & Dedicated (s) & $13 \%$ \\
\hline People that investigate natural world (s) & $11 \%$ & Interested in science $(\mathrm{s})$ & $13 \%$ \\
\hline Make the world better (s) & $11 \%$ & Go against stereotypes (n) & $12 \%$ \\
\hline Enjoy learning (s) & $11 \%$ & Discover things (s) & $12 \%$ \\
\hline Question things (s) & $10 \%$ & Rosalind Franklin (n) & $11 \%$ \\
\hline Psychologists (f) & $10 \%$ & Make the world better (s) & $11 \%$ \\
\hline Physicists (f) & $10 \%$ & Not just one type of person (n) & $11 \%$ \\
\hline \multicolumn{4}{|l|}{ B. } \\
\hline \multicolumn{2}{|c|}{ Beginning of Course Reader Homework course } & \multicolumn{2}{|c|}{ End of Course Reader Homework course } \\
\hline Most common descriptions of scientists & Prevalence & Most common descriptions of scientists & Prevalence \\
\hline Curious (s) & $32 \%$ & Curious (s) & $24 \%$ \\
\hline Especially Intelligent (s) & $18 \%$ & Especially intelligent (s) & $15 \%$ \\
\hline People that do experiments (s) & $14 \%$ & People that do experiments (s) & $14 \%$ \\
\hline Discover things (s) & $13 \%$ & Discover things (s) & $14 \%$ \\
\hline Interested in science (s) & $13 \%$ & All types of people (n) & $13 \%$ \\
\hline Enjoy learning (s) & $12 \%$ & Chemists (f) & $12 \%$ \\
\hline Albert Einstein (s) & $10 \%$ & Make the world better (s) & $12 \%$ \\
\hline Chemists (f) & $10 \%$ & Doctors (f) & $11 \%$ \\
\hline Doctors (f) & $10 \%$ & Biologists (f) & $11 \%$ \\
\hline All types of people (n) & $8 \%$ & Albert Einstein (s) & $8 \%$ \\
\hline People that investigate natural world (s) & $8 \%$ & Enjoy learning (s) & $8 \%$ \\
\hline Open-minded (s) & $8 \%$ & People that investigate natural world (s) & $8 \%$ \\
\hline Biologists (f) & $7 \%$ & Passionate (s) & $8 \%$ \\
\hline Make the world better (s) & $7 \%$ & Creative (s) & $7 \%$ \\
\hline Astronomers (f) & $7 \%$ & Geneticists (f) & $7 \%$ \\
\hline
\end{tabular}

Shading and letters in parentheses denote categories of descriptions per Schinske et al., 2015: s/turquoise = Stereotype $\mathrm{n} /$ light green $=$ Nonstereotype $\mathrm{f} /$ gray $=$ Field of Science.

students, as exemplified by Theresa's response presented earlier. Many students resorted to describing scientists simply as those individuals who participate in certain, named scientific fields or professions. For example,

The types of people who do science are teachers, professors, NASA workers, nurses, doctors, etc. NASA scientists use science to study space and the earth ... Doctors use science to study the human body.-Carlos, a Latino Course Reader Homework student

By the end of the course, most students from Scientist Spotlight classes used Nonstereotypes to describe scientists (Table 1A). Tania reflected on the ways her views of scientists changed and stated that many scientists defy stereotypes of individuals in their fields. Rather, scientists are "normal people" like her:
Before I learned about scientists in this class, I thought scientists were like "nerds" or what they show in movies. The characters would be very geeky, had glasses, spoke monotone, and thought they were above everyone. However, through all the research I've done in this class, scientists are just normal people like myself. They love to learn new things, they have a life outside the laboratory, they are fun ... My opinion of people that do science has completely changed thanks to this class.-Tania, a Filipina Scientist Spotlight Homework student

Felipe reported that people from diverse countries and socioeconomic backgrounds are scientists and that scientists did not all have an innate interest in the field from an early age:

The types of people that do science are all kinds of people. What I have learned through out this course is that it is possible to be a scientist under any circumstances, from poverty to 
being from a different country to having a stereotypical assumption about a person, for example a cheerleader. Anyone can be a scientist if they want to. One thing all scientists we learned about had in common was that they weren't interested in science until something sparked their interest.-Felipe, a Latino Scientist Spotlight Homework student

Matthew agreed that scientists need not be initially interested in science, citing the example of Carl Djerassi:

The types of people that do science vary greatly. One scientist, Djerassi, in an interview said he had no interest in science as a kid, but he eventually grew up to be the scientist that created contraceptive pills for women.-Matthew, a Vietnamese male Scientist Spotlight Homework student

Maria more specifically called attention to the fact that race and sex are not determinants of an ability to be a scientist:

\begin{abstract}
All types of people can do science ... What I learned was that your background/sex/race doesn't determine if you will become a scientist or not. It is all about the passion and love for knowledge that human beings have.-Maria, a Latina Scientist Spotlight Homework student
\end{abstract}

Cynthia, as well as Tania (noted earlier), pointed out that interests outside of science can be as important to scientists as an interest in science:

[Scientists] take their passion and often combine it with science. For example, the scientist that was looking at musician's [sic] brains as they improvised music.-Cynthia, a white female Scientist Spotlight Homework student

The above responses made the argument that many different types of people, and perhaps all types of people, are scientists. Indeed, at the end of the course, the majority of students $(55 \%)$ included descriptions of scientists fitting into at least one of the following categories: all types of people, not just one type of person, or go against stereotypes. The quotations from Cynthia and Matthew further demonstrated that, at the end of the course, many students had specific, counterstereotypical individuals in mind to inform their descriptions of scientists.

Matthew and Felipe pointed out that many scientists did not have an innate or early interest in science, and we no longer see references to scientists as especially intelligent in these exemplars. Given that we believe all of the scientists featured in Scientist Spotlights are very intelligent, we found it striking that "intelligent" and "smart" largely disappeared as ways to describe scientists (Table 1A). It appears that, while the featured scientists may still have been impressively smart, "intelligent" was no longer a significant defining feature of scientists in students' minds. Rather, scientists were considered regular/ normal people who happened to find their way to careers in science (responses of Matthew, Felipe, and Tania).

In contrast to the above findings from Scientist Spotlight students, Course Reader Homework students largely continued to use stereotypes and generalities to describe scientists at the end of the course (Table 1B). For example, Laila and Mei continued to describe scientists in terms of their special intelligence/knowledge:

People who work in science fields have absolutely incredible intelligence.-Laila, Indonesian female Course Reader Homework student

Scientists have to be up-to-date about research, medicine, diseases.-Mei, a Chinese female Course Reader Homework student

Carlos, like many other students in Course Reader Homework classes, continued to define scientists in nebulous terms through their fields/professions:

The types of people that do science are people that do astrophysics, astronomy, chemistry, biology, physics, and geophysical science. There are NASA scientists that study space. Also there are scientists that study humans and their environment.-Carlos, a Latino Course Reader Homework student

Theresa reiterated the importance of curiosity from her beginning-of-course response:

All kinds of people do science, especially those who are really curious about a certain scientific topic. Men can be scientists as well as women ... Albert Einstein is a very famous scientist.-Theresa, a white female Course Reader Homework student

Theresa and some other Course Reader Homework students did mention at the end of the course that all types of people do science, causing that description to increase in prevalence (Table 1B). It is interesting to note, however, that the remainder of Theresa's end-of-course response was nearly identical to her beginning-of-course response-emphasizing curiosity and raising the same example of Albert Einstein. In other words, while a small number of Course Reader Homework students appear by the end of the course to be describing a more inclusive version of who does science, those students' responses still lacked the specific examples and expanded descriptions of scientists we observed from Scientist Spotlight students.

In quantitatively analyzing these trends, an RM-ANCOVA revealed significant interactions between treatment and the use of Stereotypes, $F(1,311)=13.39, p<0.001, \eta^{2}=0.04$, and Nonstereotypes, $F(1,311)=16.51, p<0.001, \eta^{2}=0.05$. When looking solely at raw means, we observed all students using fewer Stereotypes at posttest, but Scientist Spotlight Homework students showed a sharper decrease, suggesting that the treatment produced a stronger decrease in Stereotype use. However, an analysis of weighted means to isolate the variability introduced by treatment condition from the variability introduced by race/ethnicity, gender, and course section, showed no significant differences in the decrease across groups. In terms of Nonstereotypes, both raw and weighted means show a significant increase among Scientist Spotlight students when compared with Course Reader Homework students (Figure 1 and Supplemental Material, parts E and F). Therefore, when controlling for unequal group sizes and nonrandom assignment, 
Treatment Effects On Nonstereotypical Descriptions of Scientists

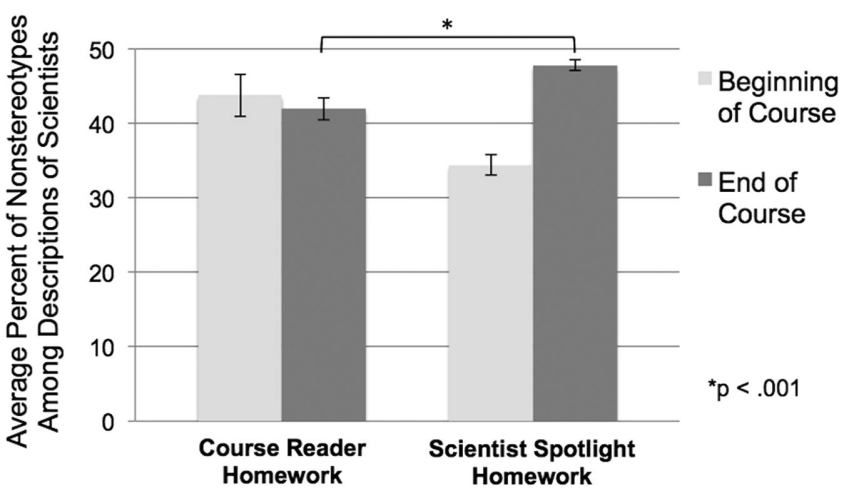

FIGURE 1. Average percent of Nonstereotypes among descriptions of scientists at the beginning vs. end of the course for Course Reader Homework and Scientist Spotlight Homework classes. Graphs depict weighted means to control for unequal group sizes and nonrandom assignment of students to treatment. Error bars represent SE.

our results suggested the completion of Scientist Spotlights was associated with increases in the use of Nonstereotypes in describing scientists.

\section{Hypothesis 2 Results: Scientist Spotlights Will Enhance Students' Ability to Personally Relate to Scientists}

Scientist Spotlight Homework submissions provided evidence of students encountering scientists to whom they could relate on a personal level. For example, Binh could relate to Flossie Wong-Staal and Juan Perilla because, like him, they were originally from outside the United States, albeit from countries different from his:

Another thing is scientists who are successful in the U.S. are not necessary [sic] born in the U.S. These scientists are both from another country but they're really successful. It makes me more confident in becoming a scientist because no one in my family is a scientist and I'm not a U.S. citizen.-Binh, a Vietnamese male student responding to the Scientist Spotlight on Flossie Wong-Staal and Juan Perilla

On the other hand, Emily could relate to Charles Limb due to shared interests outside science:

I found this Ted Talk with Charles Limb incredibly interesting mostly because I am a musician myself who has been trained both classically and in jazz.-Emily, a white female student responding to the Scientist Spotlight on Charles Limb

Anthony found Agnes Day relatable due to their shared racial/ethnic identities and because of what she represents to people like him:

For my whole life I ... wasn't exposed to any scientist who was of African American descent. That, as a fellow African American, brought me joy as it shows that African Americans are no longer abiding to the negative stigma we have. She's representing a powerful position for us and people have noticed her work. It gave me incentive to push for my own dreams and to succeed.-Anthony, a Black male student responding to the Scientist Spotlight on Agnes Day

Some of the resources students reviewed during Scientist Spotlights demonstrated that scientists experienced barriers, inequities, and marginalization or that science itself can include the study of social inequities (e.g., health disparities). These themes spurred many students, like Anthony, to connect with scientists through the lens of social justice. After learning about Ben Barres's personal story and path in science, Maria discussed her views on gender equity in science and how that relates to her experience at her community college. She further compares what she learned about the biology content in this assignment (glial cells) with the plight of women in science:

The fact that there are considerably less women in science than men, is more of a socio-cultural problem, than a genetic or gender problem. Personally, I feel optimistic, yes we are the minority in science, and are paid less then men, and are discriminated against, but when I look around my community college I see many women succeeding, and unafraid to give the best of them[selves] ... In a way glia cells are a little bit like the "women" of the nervous system; extremely important for the survival of the cells, form the majority of the nerve cells population, and are underestimated and perceived only as a "supporter" cell.-Maria, a Latina student responding to the Scientist Spotlight on Ben Barres

Gina responded to Agnes Day's scientific work by proposing that the type of science that gets done might depend largely on the type of people doing the science. As a result, diversity in the sciences might be required in order to understand the importance of, and go on to pursue, certain research areas:

Dr. Day is one of the first to complete a study in cancer concerning the differences in race. If she was not African American I do not think that Dr. Day would understand the significance of her research ... As a strong Black woman representing women and people of color in a White male driven field Dr. Day defies what I believed about people who do science. I wonder if the questions of science require diversity, collaboration and personal passions in order to be answered.-Gina, a Black/Native American female student responding to the Scientist Spotlight on Agnes Day

Beginning- and end-of-course responses to the relatability prompt additionally demonstrated distinct shifts in an ability to personally relate to scientists. Two hundred eight Scientist Spotlight Homework students and 86 Course Reader Homework students submitted both beginning- and end-of-course responses to the relatability prompt. The sample size for this prompt was smaller than that for the stereotypes prompt, since it took longer to develop and establish face validity for this prompt. As a result, it was only presented at both time points to four of the five sections of Scientist Spotlight students. The final relatability prompt stated: "I know of one or more important scientist to whom I can personally relate," which was followed by a Likert scale and a space for qualitatively explaining the opinion selected. An "I don't know" option was included in the Likert scale and was 
coded as "Disagree" based on the qualitative explanations provided by students selecting "I don't know" (e.g., "I honestly only know of one [scientist] and I'm nothing like him").

Only $35 \%$ of students in Scientist Spotlight Homework classes and 36\% in the Course Reader Homework classes either agreed or somewhat agreed with the relatability prompt at the start of the course, indicating that students did not generally feel they could relate to scientists. Students' beginning-ofcourse responses regarding their ability to relate to scientists fell into two main categories. First, as exemplified by the responses of Jesus and Evelyn, many students explicitly affirmed that they were unable to relate to scientists:

I Don't Know. I truly am terrible at relating to people that are involved with science or math.-Jesus, a Latino Scientist Spotlight Homework student

Disagree. I don't personally relate to any scientist as most of my friends and family members are not scientists.-Evelyn, a Chinese female Course Reader Homework student

Ademar and Beth clarified that this was often because students lacked familiarity with any actual scientists:

Disagree. I personally don't know any scientist, and sometimes I cannot see myself having the personal qualities of a scientist.-Ademar, a Latino Course Reader Homework student

I Don't Know. I'm not very familiar with scientists or their names and studies._-Beth, a Black/Latina female Course Reader Homework student

Second, among the few students who indicated at the beginning of the course they could personally relate to scientists, many, like Yvette, explained this was simply because they appreciated the types of work scientists did:

Somewhat Agree. I am knowledgeable of various scientists but I don't feel personally relatable to them. I appreciate their work and what it has done to better inform us as a society.-Yvette, a Latina Scientist Spotlight Homework student

At end of the course, 79\% of Scientist Spotlight Homework students agreed or somewhat agreed that they could personally relate to an important scientist. These students' end-of-course explanations differed markedly from their beginning-of-course responses and included many details as evidence for relating to (or not relating to) scientists. Two main themes arose as reasons students related to scientists at the end of the course. First, many students found they could relate to scientists due to shared interests or personal qualities. Lauren described how she could relate to Charles Limb due to common interests surrounding music:

Agree. I relate the most with the neurologist/musician from the first scientist spotlight ... because I am also a musician.-Lauren, a white female Scientist Spotlight Homework student

Jesus, on the other hand, related to Lawrence David due to a shared sense of humor, an interest in making others laugh, and a similar work ethic:
Somewhat Agree. I can relate to that one scientist who interacted with poop. I loved his sense of humor and drive to complete an experiment ... I know that I can relate to him because I love being funny to make people smile and also am determined to work on things until I finish.-Jesus, a Latino Scientist Spotlight Homework student

Second, some students found scientists relatable if the scientists did not originally expect to enter a career in science. Yvette found she could relate to many of the scientists for this reason and further explains that she is similarly reconsidering her interest in studying science:

Somewhat Agree. In some of the spotlights some scientists felt that they didn't always want to pursue a career in science and that it just happens. I'm starting to feel the same way. I'm not originally a science major but I feel that I could have a future in it if I find the right field.-Yvette, a Latina Scientist Spotlight Homework student

While a less common theme, seeing scientists with matching genders or races/ethnicities was important in making them relatable for some students, like Rachel:

Somewhat Agree. Although I might not be that interested in pursuing a career in science, being exposed to a wide variety of diverse scientists, I feel like I could go into this field if I wanted to. Many of the scientists we learned about were women and many were a race other than White. These are both characteristics I would use to describe myself.-Rachel, a Filipina Scientist Spotlight Homework student

Others, like Tammy, indicated that it made scientists more relatable to see they have encountered similar struggles or injustices in life:

Agree. I can relate the most to Ben Barres because of the obvious discrimination he received as a woman. Being the older sister of a very bright brother, I am often compared to him and overlooked for my intelligence. Unless it comes from him, my opinion is just that of a woman.-Tammy, a Black/Native American female Scientist Spotlight Homework student

As seen in earlier quotes, many students at the end of the course were able to name or describe specific scientists in their responses, suggesting greater familiarity. Of course, this familiarity did not always result in relatability. Amit simply could not envision himself having the same passion for science:

Disagree. In our scientist spotlights, all the scientists came from very different backgrounds. However, they all liked science very much. I can't relate to that. I don't have any particular disdain for science, but I don't enjoy it. I do think it is very important, however.-Amit, an Asian Indian male Scientist Spotlight Homework student

This presented a barrier to finding scientists relatable, even when recognizing the featured scientists were very diverse. On the other hand, notable shifts in qualitative responses toward an increased ability to relate to scientists were sometimes observed even among students whose Likert-scale relatability 
selections did not change (e.g., Yvette, who selected "somewhat agree" at both the beginning and end of the course).

Only 43\% of Course Reader Homework students agreed or somewhat agreed with the relatability prompt at the end of the course. End-of-course qualitative responses from these students were strikingly similar to their beginning-of-course responses, with many students, like Evelyn and Beth, using language identical to what they had written at the beginning of the course:

I Don't Know. None of my friends or family members are scientists.-Evelyn, a Chinese female Course Reader Homework student

Somewhat Disagree. I am not very familiar with scientists.-Beth, a Black/Latina female Course Reader Homework student

Responses reiterated beginning-of-course themes that most students could not relate to, and did not even know of, any scientists. This was in spite of the fact that some scientists were introduced as part of certain lectures during Course Reader Homework classes (see Methods).

Following an RM-ANCOVA, we observed an interaction between treatment $\times$ time for relatability Likert-scale ratings on the relatability prompt, $F(1,276)=8.49, p=0.004, \eta^{2}=0.03$. Course Reader Homework students' end-of-course relatability Likert scores did not differ significantly from their beginning-ofcourse scores, while Scientist Spotlight students' end-of-course relatability scores were significantly higher than both their own beginning-of-course scores and Course Reader Homework participants' end-of-course scores (Figure 2 and Supplemental Material, parts E and F). Quantitative results therefore support the hypothesis that Scientist Spotlights increase students' sense of relating to scientists.

\section{Evidence Regarding Longitudinal Impacts of Scientist Spotlights on Stereotypes and Relatability}

Fifty-seven Scientist Spotlight Homework students submitted a response to the stereotypes prompt 6 months after the end of

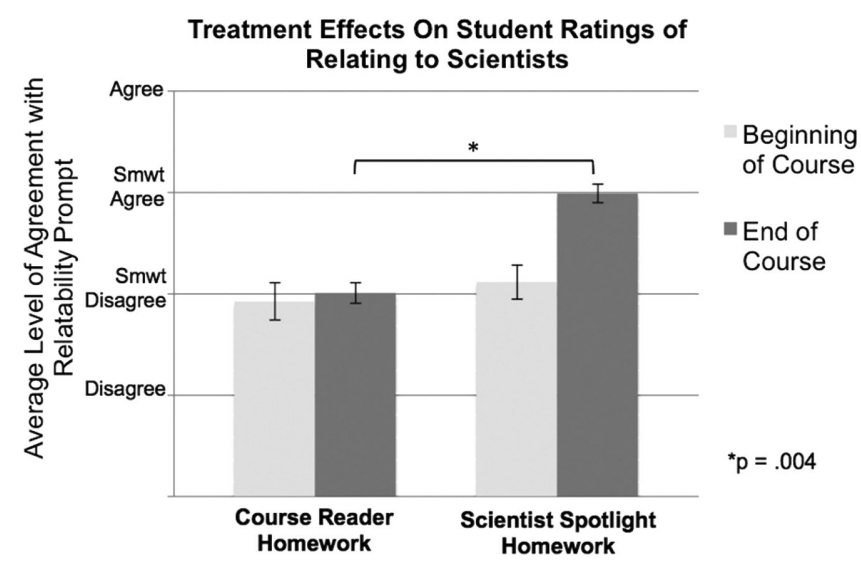

FIGURE 2. Average relatability Likert-scale selections by students at the beginning vs. end of the course for Scientist Spotlight Homework and Course Reader Homework classes. Graphs depict weighted means to control for unequal group sizes and nonrandom assignment of students to treatment. Error bars represent SE. their courses (17\% response rate). Of those, 47 had submitted responses to the stereotypes prompt at all three time points (beginning of term, end of term, 6 months after class). Fifty-two students submitted a response to the relatability prompt 6 months after the end of their courses (15\% response rate). Of those, 27 had submitted responses to the relatability prompt at all three time points. As the community college student population is in constant flux, with students transferring to 4-year schools or professional programs, moving between colleges, and entering and exiting school at various times due to work and family obligations, we were not surprised by the modest response rate to a survey 6 months after the end of class. In spite of these lower sample sizes, however, this 6-month follow-up subsample appeared to match the larger sample in terms of demographics. Three independent $t$ tests for gender, race/ethnicity (traditionally underserved vs. traditionally well served), and condition demonstrated that gender, $t(279)=-0.655, p=0.513$, and race/ ethnicity, $t(69.87)=0.908, p=0.367$, were similar between the 6-month follow-up sample and the larger, original sample.

Six months after the end of class, students appear to have maintained the largely nonstereotypical ideas about scientists they displayed at the end of the course. Table 2 shows the most prevalent themes found in responses to the stereotypes prompt from students who submitted essays at all three time points. We additionally created word clouds to visually convey the full range of scientist descriptions at each time point (Supplemental Material, part I). Descriptions of scientists as representing many/all types of people remained the most common theme in the 6-month postclass responses. Students additionally continued to describe scientists as individuals who defy stereotypes, and the idea that scientists have "special intelligence" continued to be relatively rare. Fifty-seven percent of students included descriptions of scientists fitting into at least one of the following categories 6 months after the course: all types of people, not just one type of person, and go against stereotypes.

Three-way RM-ANCOVAs controlling for gender and race/ ethnicity (Supplemental Material, parts E and F) showed that stereotypical descriptions dropped significantly at the end of the course and remained low 6 months later, $F(2,78)=4.36$, $p=0.016, \eta^{2}=0.10$ (Figure 3a). Nonstereotypical descriptions increased significantly at the end of the course and remained high 6 months later, $F(2,80)=5.97, p=0.004, \eta^{2}=0.13$ (Figure $3 \mathrm{~b})$. Relatability similarly increased at the end of the course and remained high 6 months later, though in this case the initial increase was detected at a $p$ value of $0.083, F(2,46)=2.63$, $p=0.083, \eta^{2}=0.10$ (Figure $3 c$ ). This was likely because of the smaller sample size available for the relatability prompt.

\section{Hypothesis 3: Shifts in Scientist Stereotypes and Relatability of Scientists Will Correlate with Students' Interest in Science}

We calculated both beginning- and end-of-course Science Interest scores (Supplemental Material, parts G and H) for each student. To test the relationship between shifts in Science Interest and shifts toward majoring in STEM fields, we conducted a $2 \times 2$ (Science Interest $\times$ STEM major interest) RM-ANCOVA controlling for gender, race/ethnicity, course section, and prior science class experience. Values for STEM major interest came from the online survey item "I am majoring or plan on majoring in another Science or Math field" (Supplemental Material, part D). 
TABLE 2. Most common student descriptions of scientists from the beginning of the course, the end of the course, and 6 months after the end of the course

\begin{tabular}{|c|c|c|c|c|c|}
\hline \multicolumn{2}{|c|}{ Beginning of Scientist Spotlight courses } & \multicolumn{2}{|c|}{ End of Scientist Spotlight courses } & \multicolumn{2}{|c|}{ Six months after Scientist Spotlight courses } \\
\hline $\begin{array}{l}\text { Most common descriptions } \\
\text { of scientists }\end{array}$ & Prevalence & $\begin{array}{l}\text { Most common descriptions } \\
\text { of scientists }\end{array}$ & Prevalence & $\begin{array}{c}\text { Most common descriptions } \\
\text { of scientists }\end{array}$ & Prevalence \\
\hline Curious (s) & $27 \%$ & All types of people (n) & $41 \%$ & All types of people (n) & $47 \%$ \\
\hline Albert Einstein (s) & $24 \%$ & Not just one type of person (n) & $29 \%$ & Not just one type of person (n) & $20 \%$ \\
\hline Especially intelligent (s) & $22 \%$ & Interested in science (s) & $24 \%$ & Curious (s) & $18 \%$ \\
\hline People that do experiments (s) & $18 \%$ & Passionate (s) & $24 \%$ & Make the world better (s) & $18 \%$ \\
\hline Discover things (s) & $18 \%$ & Cheerleaders (n) & $22 \%$ & Discover things (s) & $18 \%$ \\
\hline Interested in science (s) & $14 \%$ & Darlene Cavalier (n) & $18 \%$ & Passionate (s) & $16 \%$ \\
\hline Make the world better (s) & $14 \%$ & Curious (s) & $16 \%$ & Go against stereotypes (n) & $16 \%$ \\
\hline Enjoy learning (s) & $12 \%$ & People that do experiments (s) & $16 \%$ & Dedicated (s) & $14 \%$ \\
\hline Question things (s) & $12 \%$ & Discover things (s) & $16 \%$ & Rosalind Franklin (n) & $12 \%$ \\
\hline $\begin{array}{l}\text { People that investigate natural } \\
\text { world (s) }\end{array}$ & $10 \%$ & $\begin{array}{l}\text { People from outside the United } \\
\text { States (n) }\end{array}$ & $14 \%$ & Interested in science (s) & $10 \%$ \\
\hline Chemists (f) & $10 \%$ & Rosalind Franklin (n) & $12 \%$ & People that do experiments (s) & $8 \%$ \\
\hline Psychologists (f) & $10 \%$ & James Watson (s) & $12 \%$ & Struggled financially (n) & $8 \%$ \\
\hline Doctors (f) & $10 \%$ & Go against stereotypes (n) & $12 \%$ & Creative (s) & $6 \%$ \\
\hline People that look for "truths" (s) & $8 \%$ & Creative (s) & $10 \%$ & Enjoy learning (s) & $6 \%$ \\
\hline Biologists (f) & $8 \%$ & $\begin{array}{l}\text { Not always interested in } \\
\text { science (n) }\end{array}$ & $10 \%$ & $\begin{array}{l}\text { People that investigate natural } \\
\text { world (s) }\end{array}$ & $6 \%$ \\
\hline
\end{tabular}

Shading and letters in parentheses denote categories of descriptions per Schinske et al., 2015: s/turquoise = Stereotype; $\mathrm{n} /$ light green = Nonstereotype; f/gray = Field of Science.

A significant interaction for Science Interest was found, $F(1,216)$ $=10.39, p=0.001, \eta^{2}=0.05$, in which students whose Science Interest decreased or held steady showed a significant decrease in STEM major interest from pretest $(\bar{x}=3.70, \mathrm{SE}=0.16)$ to posttest $(\bar{x}=3.43$, SE $=0.18)$, while students whose Science Interest increased reported more STEM major interest at posttest $(\bar{x}=3.34, \mathrm{SE}=0.16)$ than at pretest $(\bar{x}=3.74, \mathrm{SE}=0.18)$.

RM-ANCOVAs using the Science Interest scale (Supplemental Material, parts E and F) revealed that a decrease in the use of Stereotypes correlated with higher Science Interest at the end of the course, $F(1,182)=4.46, p=0.036, \eta^{2}=0.02$ (Figure 4a). We found a similar relationship between an increase in the use of Nonstereotypes and Science Interest that approached significance, $F(1,182)=3.32, p=0.070, \eta^{2}=0.02$ (Figure $4 b$ ). Science Interest additionally appeared to increase from beginning of course $(\bar{x}=3.287, \mathrm{SE}=0.076)$ to end of course $(\bar{x}=3.568$, $\mathrm{SE}=0.061)$ for students whose ability to relate to scientists increased, but this finding did not achieve statistical significance, $F(1,184)=2.10, p=0.149, \eta^{2}=0.01$. In total, these results provide partial support for the hypothesized relationship between shifts in scientist stereotypes/relatability and an interest in science/STEM majors.

\section{Hypothesis 4: Shifts in Scientist Stereotypes and Relatability of Scientists Will Correlate with Course Grades} As a first step, we tested whether the treatment had an effect on course grades. A one-way ANCOVA, controlling for gender, race/ethnicity, course section, and previous science class experience, revealed that Scientist Spotlight Homework students earned significantly higher grades than Course Reader Homework students, $F(1,279)=6.68, p=0.018, \eta^{2}=0.02$ (Figure 5a and Supplemental Material, parts E and F).

Additional analyses were limited to Scientist Spotlight Homework students to prevent confounds introduced by the treatment. One-way ANCOVAs suggested there was not a significant effect for the use of Stereotypes on grades, $F(1,211)=3.00$, $p=0.085, \eta^{2}=0.01$, but there was a significant effect of Nonstereotypes, $F(1,211)=6.68, p=0.010, \eta^{2}=0.03$. Students whose use of Nonstereotypes increased earned significantly higher course grades than those whose use of Nonstereotypes held steady or decreased (Figure 5b and Supplemental Material, parts $\mathrm{E}$ and F). To test the relationship between relatability and course grade, we compared students whose relatability ratings increased, those whose relatability ratings decreased, and those whose ratings held steady. A one-way ANCOVA controlling for race/ethnicity, gender, course section, and science experience, suggested the grades of students whose ratings decreased $(\bar{x}=2.59, \mathrm{SE}=0.24)$ were lower than students whose ratings held steady $(\bar{x}=2.79, \mathrm{SE}=0.15)$ or increased $(\bar{x}=3.01, \mathrm{SE}=$ $0.10)$. However, the difference between groups was not significant, $F(1,171)=1.65, p=0.195, \eta^{2}=0.02$. The finding of a correlation between an increase in Nonstereotypes and course grades therefore provided partial support for hypothesis 4 .

\section{DISCUSSION}

Many reports have documented the shortfall in students graduating with STEM degrees in the United States and the urgent need to recruit a more diverse STEM workforce (National Academy of Sciences, 2007, 2011). Interventions with the potential to enhance students' science identities and reduce stereotype threat could prove valuable in promoting interest and success in STEM (Seymour and Hewitt, 1997; Brickhouse et al., 2000; Hill et al., 2010, chap. 3; Beasley and Fischer, 2012). We developed and tested an intervention in the form of weekly homework assignments that were aimed at allowing students to see their possible selves in science and promoting counterstereotypical examples of who does science. In the following sections, we discuss the utility of Scientist Spotlights in light of our 
(a) Longitudinal Trends in Stereotypical Descriptions of Scientists Following Scientist Spotlights

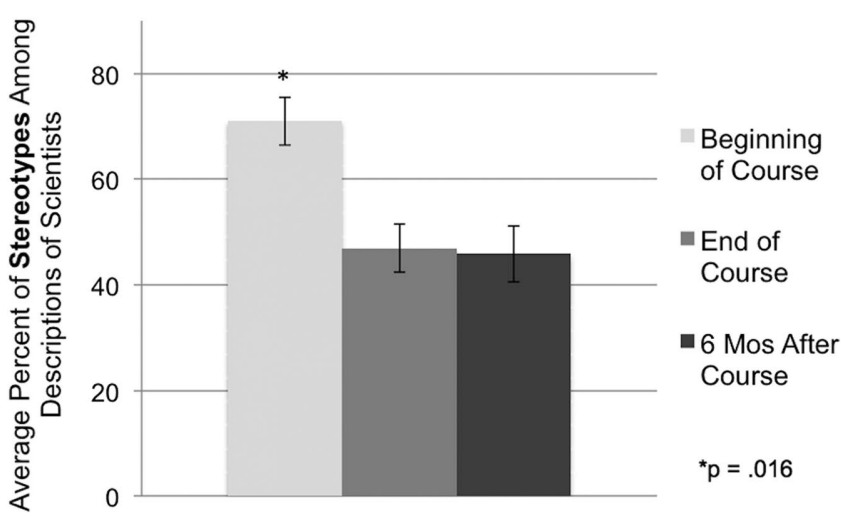

(b) Longitudinal Trends in Nonstereotypical Descriptions of Scientists Following Scientist Spotlights

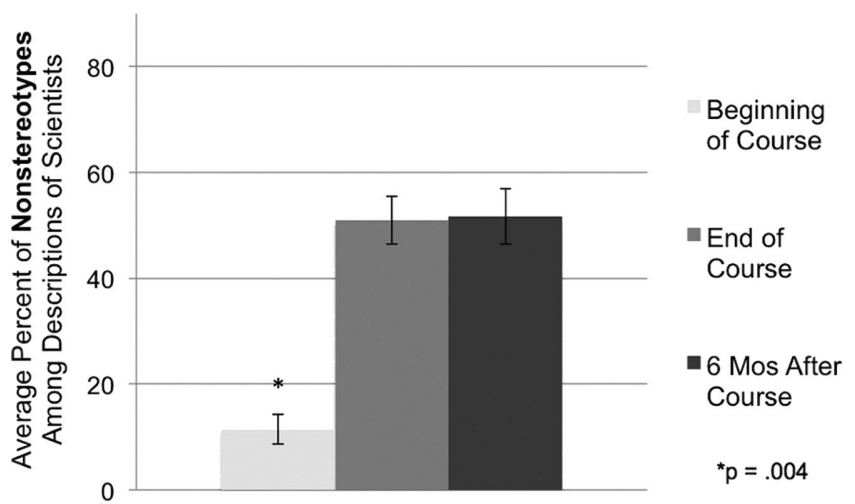

(c) Longitudinal Trends in Student Ratings of Relating to Scientists Following Scientist Spotlights

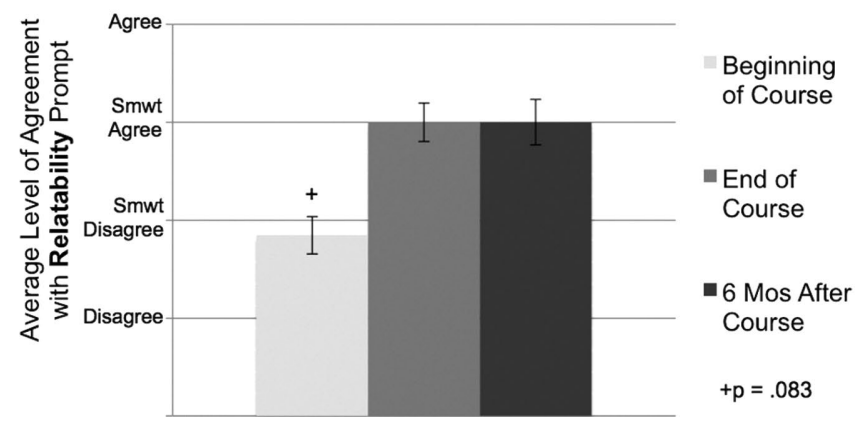

FIGURE 3. Average percent of Stereotypes (a), percent of Nonstereotypes (b), and relatability Likert-scale selections (c) in Scientist Spotlight students' responses at the beginning of the course, end of the course, and 6 months following the end of the course. Error bars represent SE.

findings, factors that may influence the effectiveness of Scientist Spotlights, and our anticipated future directions in exploring Scientist Spotlights.

\section{Scientist Spotlights Generated Shifts in Students'} Stereotypes of Scientists and Scientist Relatability We used the stereotypes prompt to evaluate the impact of Scientist Spotlights on students' stereotypes of scientists. When

\section{(a) Changes in Stereotypical Descriptions of Scientists \& Changes in Science Interest}

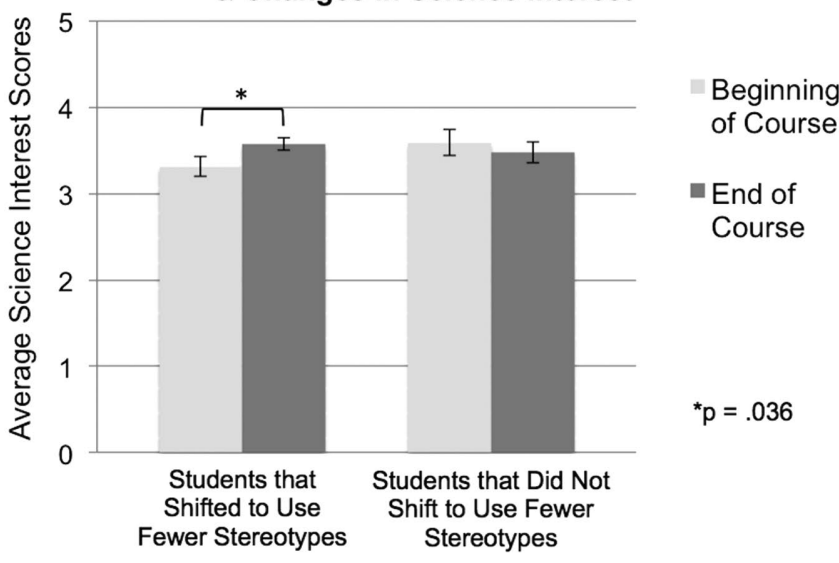

(b) Changes in Nonstereotypical Descriptions of Scientists \& Changes in Science Interest

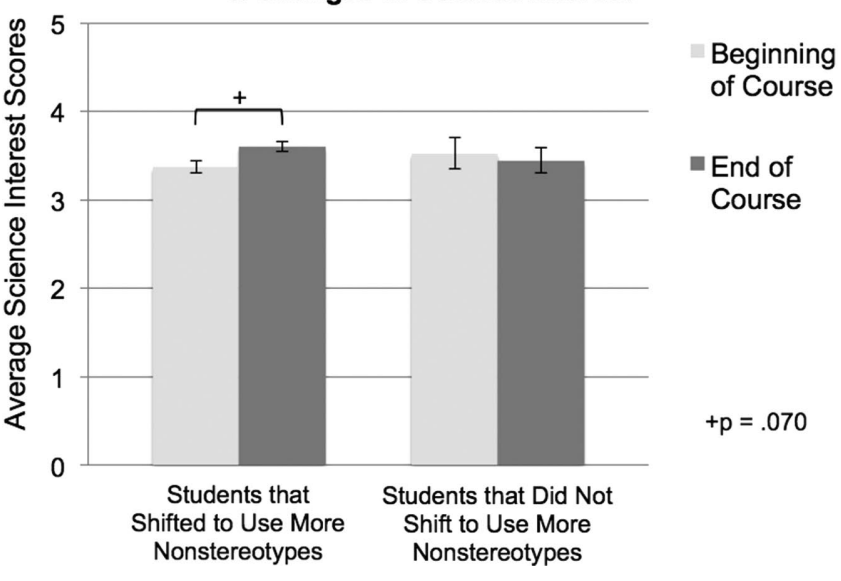

FIGURE 4. Relationships between changes in Stereotypes (a) and Nonstereotypes (b) to changes in Science Interest from the beginning of the course to the end of the course.

compared with a class performing a similar activity that lacked connections with diverse scientists, students who completed Scientist Spotlights adopted more nonstereotypical views of scientists (Figure 1). These changes appeared to be sustained 6 months after the courses ended (Figure 3 ) and were associated with higher course grades (Figure 5). Reductions in stereotypical descriptions of scientists further correlated with increases in Science Interest (Figure 4a) and an enhanced interest in STEM majors.

We piloted the relatability prompt as a tool for examining students' possible selves in a science context, making the case that explicitly asking students about their ability to personally relate to scientists would draw out descriptions of students' possible selves in relation to scientists. While only $43 \%$ of Course Reader Homework students found scientists relatable at the end of the course, the vast majority (79\%) of Scientist Spotlight students did (Figures 2 and 4c). These students discussed shared personalities and interests outside science as reasons for being able to relate to scientists, with some students also commenting on certain scientists' nontraditional paths to gaining an interest in science. Many students used specific language such 


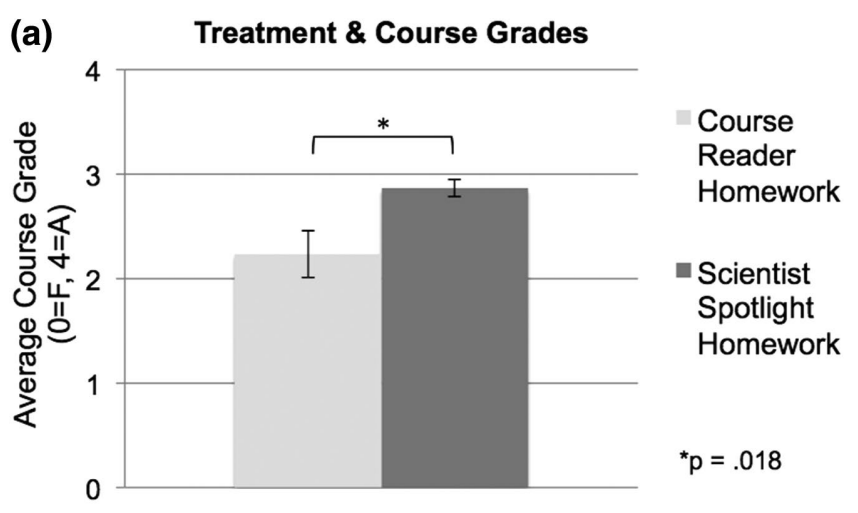

(b) Shifts In Use of Nonstereotypical Descriptions of

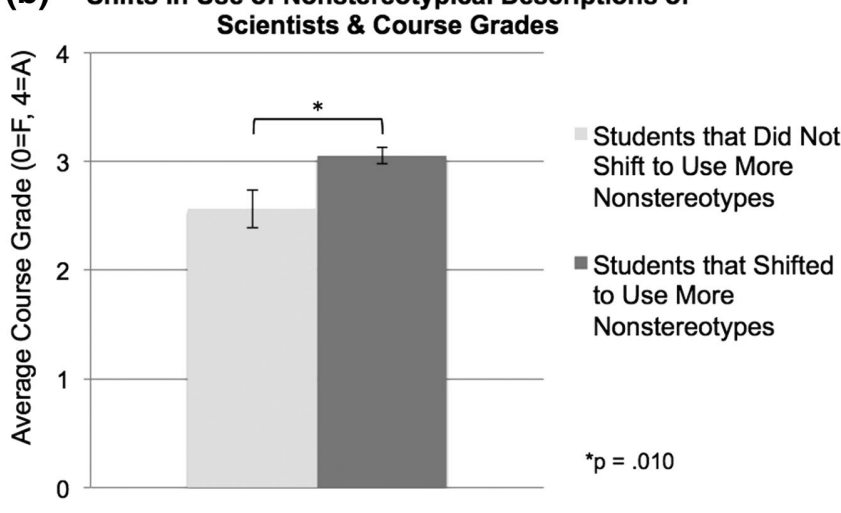

FIGURE 5. Average course grades ( $0=$ "F," 4 = "A") for Scientist Spotlight Homework students vs. Course Reader Homework students (a) and for students whose proportion of Nonstereotype descriptions of scientists increased vs. did not increase (b). Error bars represent $\mathrm{SE}$.

as "like me" or "I am also ..." when describing why common interests or personal qualities caused them to relate to scientists after Scientist Spotlights. This suggested the relatability prompt might have functioned as intended in creating opportunities for students to reflect on their possible science selves.

These findings suggest Scientist Spotlights hold promise as a tool for enhancing students' possible science selves and disrupting stereotypes of scientists in diverse classroom settings. Prior studies point to the importance of these shifts in forming a science identity, mitigating stereotype threat, and enhancing student interest and success (Steele, 1997; Oyserman et al., 2006; Steinke et al., 2009; Hill et al., 2010, chap. 3; Hunter, 2010; Beasley and Fischer, 2012; Mills, 2014).

\section{Scientist Spotlights Represent a Simple Means for Raising Issues of Diversity in STEM Classrooms}

Faculty might feel particularly wary of adopting new activities that overtly approach issues related to race and diversity due to a lack of training in how to facilitate discussions in those areas (Sue et al., 2009). STEM faculty commonly cite course content expectations and concerns regarding time as barriers to implementing innovative teaching strategies (Henderson and Dancy, 2007; Austin, 2011). Scientist Spotlights offer faculty an approach for openly addressing diversity in STEM classes while supporting content goals and requiring little grading or class time.
Because Scientist Spotlights are assigned as homework and are graded based on timeliness and word count, the activities consume only a negligible amount of instructor time during and outside of class. This is perhaps particularly the case when they are assigned through an online course management system that automatically displays word counts. After an initial investment of time to identify scientists to feature and compose assignment prompts, Scientist Spotlights become an easily sustainable class activity.

Additionally, by connecting diversity themes to course content through Scientist Spotlights, faculty are able to structure some of students' content learning outside class. In this way, Scientist Spotlights assist faculty in meeting their content expectations, rather than taking time away from addressing content. This follows the best practices discussed by Chamany et al. (2008), who recommend "strategically embedding social context into those topics that are traditionally reviewed in ... biology courses." Highlighting the struggles and inequities experienced by scientists like Ben Barres also opened up opportunities for students to engage with issues of social justice in science. Infusing course content with themes of equity and social justice has been promoted as a particularly impactful way to engage traditionally underserved and underprivileged populations of students in STEM (Chamany, 2006; Chamany et al., 2008). At the same time, these themes of equity and diversity were clearly contextualized within instructors' comfort zone of course content, which might allay instructor reservations about raising such themes as part of a STEM class.

We predict that the strongest case for faculty adoption of Scientist Spotlights, and eventually adoption of more extensive diversity-related activities, might come from students themselves once faculty pilot Scientist Spotlights. Students in our sample responded so immediately and effusively to Scientist Spotlights, it appeared there was a great, unmet demand among students to approach science content through this lens. We predict that, if faculty see responses from their own students similar to those shown here, they will feel energized and empowered to become more deeply involved in addressing diversity. Scientist Spotlights might therefore represent an excellent introductory tool that could inspire further work on equity and diversity in STEM by science faculty.

\section{Suggestions for Implementation}

While Scientist Spotlights are relatively simple activities, successfully implementing them in a course likely depends in part on how an instructor chooses scientists to feature, writes the assignment prompts, introduces the assignments to the class, and reports back on students' submissions. In the following sections, we elucidate some of the factors we feel assisted in achieving positive outcomes and reducing the potential for student resistance.

\section{Possible Selves as a Framework for Selecting Scientists to Feature in Spotlights}

We found the concept of possible selves to be helpful in identifying scientists to feature. Rather than looking for scientists to serve as role models that students should emulate, we sought out scientists with whom students might already have similarities; that is, scientists in whom students might see their possible selves. While gender/race/ethnic matching was important for 
some students, students more often cited shared personal qualities and outside interests as ways in which they saw themselves in scientists. Given that Human Biology primarily serves nonbiology majors, it is not surprising that students also appreciated that not all scientists aspired to a science career at a young age and sometimes found science later in life. In consideration of the above, it is important to identify scientists for whom some sort of engaging biographical resource exists. It was in those biographical resources that students most directly encountered counterstereotypical information about scientists and found information that reminded students of themselves. We optimally hoped to find TED Talks, interviews, or podcasts featuring scientists telling their own stories in their own voices. However, we sometimes used printed interviews and biographical information, as in the example regarding Ben Barres (see Methods). The Story Collider (www.storycollider.org/podcasts) proved a particularly rich resource for identifying biographical information regarding counterstereotypical scientists. The Story Collider website includes hundreds of 10- to 20-min-long, often funny or emotionally stirring autobiographical stories told by diverse scientists. The podcast descriptions can be searched for certain key terms through the website, which can be helpful in identifying scientists working in areas connected with course content.

\section{Metacognition as a Design Feature of Scientist Spotlight Prompts}

In terms of the assignment prompt itself and the regularity of the assignments, our work suggests that performing Scientist Spotlights regularly and including a metacognitive question about who does science assisted in achieving the outcomes we observed. Course Reader Homework classes included three references to scientists working in the fields being studied in class (see Methods). Two of those scientists identified as people of color and all three had counterstereotypical qualities. Students were introduced to those scientists during class, saw pictures of the scientists, and watched short videos featuring two of the scientists. However, students did not engage in any individual or group activities regarding the scientists and were not asked to reflect on whether those segments of class impacted their views of scientists. Our results suggested these students did not substantially change their views of scientists. This suggests that going beyond simply mentioning/showing diverse scientists in class and moving to require regular work including metacognition about who does science might be key for stimulating larger changes in the ways students view scientists. Science faculty are increasingly aware that metacognition is necessary to drive lasting changes in students' ideas and behaviors (Tanner, 2012). We therefore propose that the prompt reading, "What do these resources tell you about the types of people that do science?," might be important to include in every Scientist Spotlight assignment, even if the other writing prompts vary from one assignment to the next.

\section{Instructor Talk as a Strategy for Securing Student Buy-In}

Alongside content expectations and time limitations, fear of student resistance represents another of the main barriers to the adoption of new teaching strategies by faculty (Henderson and Dancy, 2007; Seidel and Tanner, 2013). We encountered very little evidence of student resistance to completing Scientist Spotlights in these classes. Students completed Scientist Spot- lights at very high rates, earned high scores, and seemed to find the assignments engaging and helpful. Students' acceptance of Scientist Spotlights might partially relate to the flexibility students had to engage with either the course content part of the activity or the scientist biography part of the activity. Students were allowed to independently determine how much of their submissions focused on the "types of people that do science" prompt compared with the course content-related prompts. In this way, students could settle into their own comfort zones of discussing issues of content versus issues of diversity and scientist stereotypes.

The non-content language instructors use to frame new activities and debrief completed activities ("instructor talk") might additionally play a large role in reducing student resistance and creating effective environments for applying innovative strategies (Seidel et al., 2015). While Scientist Spotlights are largely out-of-class activities, J.N.S. spent a small amount of class time at the start of the course establishing a classroom culture conducive to performing Scientist Spotlights and explaining his pedagogical decision to use these assignments. Specifically, he made clear his reasons for incorporating Scientist Spotlights into the course and his goals for the assignments, expressed that there were no "right" or "wrong" ways to respond, and noted that students could write about whatever parts of the assignments resonated most strongly with them each week. They need not strictly respond to each assignment prompt in equal amounts or in the order shown.

Following the first and second Spotlights, J.N.S. spent $\sim 5$ minutes in class sharing anonymous student quotes to demonstrate how different students engaged with course content and reflected on their notions of scientists through the assignments. J.N.S. especially looked for quotes similar to Gina's (discussed earlier) demonstrating the importance of the types of people who do science to the types of scientific questions that get pursued. This showed students in their own words that diversity is necessary to ensure diverse scientific questions are addressed and that it is important to understand who does science when considering what currently is and is not known about the topics studied in class.

\section{Limitations}

While quasi-experimental studies can represent a robust means of addressing education research questions, it is critical to explore alternate explanations for outcomes that might stem from the lack of random assignment to quasi-experimental groups (Shadish et al., 2002). Though the course sections we studied were equivalent in many respects, they differed slightly in student demographics, timing during the year, and lecture location. It is possible, for example, that differences observed between Scientist Spotlight Homework and Course Reader Homework groups were influenced by slight variations in student racial/ ethnic or gender identities between those groups. This would confound our ability to attribute differences to our intervention. Similar scenarios could be proposed for differences in lecture locations or timing during the year. However, all lecture rooms were similarly appointed and neither treatment group was isolated to a single part of the year. The five Scientist Spotlight courses took place throughout the year (three Fall classes, one Winter class, one Spring class), while one Course Reader Homework class took place in the Fall and the other in the Spring. 
Though differences between the courses appeared relatively subtle, we used statistical corrections to partition out variance introduced by demographics, course section differences, and the unequal sizes of quasi-experimental groups (i.e., lower number of Course Reader Homework students). The resulting "weighted means" were used in evaluating our hypotheses. These weighted means often differed substantially from means observed in our raw data (Supplemental Material, part E). This provided us more assurance that the differences we observed were due to the Scientist Spotlights but at the cost of variability that may have demonstrated a more robust effect. As a result, it might be argued that our results provide only conservative estimates of the impacts of Scientist Spotlights due to overly aggressive statistical corrections. That said, some researchers argue that statistical corrections are still insufficient to account for a lack of randomization, and issues with unequal group characteristics could confound the ability to make strong inferences (Shadish et al., 2002).

Other differences between our quasi-experimental groups included drop/fail/withdrawal (DFW) rates and the fact that one Course Reader Homework group was cotaught with a second instructor. From our results, it is apparent that $72 \%$ of Scientist Spotlight Homework students submitted both a beginning- and end-of-course stereotypes prompt essay, but only $67 \%$ of Course Reader Homework students did so. This might partially relate to differences in DFW rates between Scientist Spotlight and Course Reader Homework classes, effectively resulting in higher attrition in Course Reader Homework classes. Scientist Spotlight Homework classes had a 20\% DFW rate compared with a $23 \% \mathrm{DFW}$ rate in Course Reader Homework classes (for reference, the average DFW rate across all Human Biology classes at this college is $29 \%$ ). It is also possible that Course Reader Homework students were less engaged in class, causing more of them to miss one of the days when a survey was scheduled. In either case, if the lower response rate among Course Reader Homework classes occurred disproportionately among students who shifted toward higher levels of Nonstereotypes/relatability, then attrition in those classes could partly account for differences observed between quasi-experimental groups. This scenario seems unlikely, however, given that our findings suggest students conveying higher levels of Nonstereotypes and relatability have increased success in class (Schinske et al., 2015; current study). It seems more likely that attrition could have masked larger differences between our groups by eliminating additional data points for Course Reader Homework students who did not shift in these variables.

It is also possible that the addition of a coteacher for one Course Reader Homework section influenced these differences between groups as well as our results. However, J.N.S. maintained control over relevant course assignments in all sections, and the cotaught section was equivalent to the others in terms of its curriculum expectations and types of class activities. Further, we included course section as a covariate in analyses to control for course-level differences. While we observed significant variation in dependent variables among students, we did not observe such variation between course section groups.

With regard to descriptions of scientists reported from student essays, our study did not seek to establish certain descriptions as "good" and others as "bad" in relation to enhancing success or interest in biology. While some studies have categorized certain scientist stereotypes as "positive" and "negative" (Mead and Metraux, 1957), we did not explore students' cultural evaluations of specific stereotypes and cannot conclude whether individual students view such associations positively or negatively. Further surveys and interviews would be necessary to evaluate the deeper meanings and relative importance of various descriptions within the Stereotypes and Nonstereotypes categories. It should additionally be noted that our results do not provide specific insights regarding the mechanism(s) behind the outcomes observed surrounding Scientist Spotlights. Future work could explore the roles of metacognition, stereotype threat reduction, identification of possible selves, and other factors as mechanisms underlying these results.

Other possible limitations involve our proposed assessment of students' possible science selves and the nature of our survey activities more generally. We used the concept of "relatability" as a means of capturing possible selves, making the case that the prompt explicitly asked students about whether they could relate to a scientist they knew. This was an exploratory narrative approach, and whether it fully captures a student's sense of their own potential talents and abilities as scientists is a question for further exploration. Our measure was also limited in its ability to capture how students thought of themselves in terms of the characteristics of scientists they named. A more precise measure of students' sense of self-as-scientist could be helpful to expand upon and clarify the present findings.

Finally, results presented in this paper might not be broadly generalizable to all school settings. Qualitative studies have the strength of more deeply exploring student ideas but can lack the generalizability of some quantitative studies (Johnson and Christensen, 2008, pp. 441-442). We conducted our study in the unique environment of a large, diverse community college in the San Francisco Bay Area. One might anticipate different results or student reactions in less diverse settings in different parts of the United States. The types of exemplar quotes we report and the frequencies of themes we observed in students' essays, therefore, might be specific to our student population and teaching context.

\section{Future Directions}

We envision multiple opportunities to extend this work in the future, ranging from further explorations of the present findings in Human Biology classes to dissemination of the intervention across new institutions and teaching contexts. In light of the limitations discussed in the previous section, pursuing study designs that match students to quasi-experimental groups or randomize participants could reveal further significant trends and more fully illuminate the impacts of the intervention. Assessing Scientist Spotlights in additional class contexts would assist in exploring the generalizability of our findings. We also believe further explorations of the relatability prompt and other measures that might evaluate students' possible science selves could yield valuable insights into broadening participation in STEM. For example, while we observed intriguing trends connecting shifts in relatability to broader student outcomes, such as higher Science Interest and course grades, these trends did not achieve statistical significance. Further studies of relatability would assist in more fully illuminating its connections to these broader outcomes and clarifying its relationship to the broader concept of possible science selves. 
Future studies might additionally more directly explore the impacts of Scientist Spotlights on stereotype threat or classroom equity gaps. That certain shifts related to Scientist Spotlights correlated with increased Science Interest and higher course grades is encouraging and raises interesting questions about how students of different genders and races/ethnicities experienced these outcomes. However, our unequal group sizes and the nonrandom distribution of students among conditions prevented us from drawing conclusions along these lines. Further, the trends we observed in Science Interest were in relation to shifts in stereotypes/relatability, not treatment effects. Observing treatment effects related to Science Interest might require more robust controls and might be assisted by studies exploring students' sense of themselves as scientists in relation to Science Interest. Additional longitudinal data would also assist in understanding the enduring impacts of Scientist Spotlights. Longer-term follow-up data from both Scientist Spotlight students and control students would allow us to investigate how sustained shifts in stereotypes and relatability correlate with motivation and behavior in the future, specifically as they relate to pursuing and persisting in STEM majors.

Perhaps the most exciting extension of this work involves engaging additional faculty in the creation and deployment of Scientist Spotlights in new institutional and classroom contexts. Through our workshops and presentations at conferences, a wide array of faculty from diverse STEM (and non-STEM) fields have expressed interest in using Spotlights in class. The only somewhat time-consuming step in using Scientist Spotlights is the work done before the start of a course to select scientists, gather appropriate scientific and biographical resources regarding the scientists, and compose the assignment prompts. It might therefore be useful to nucleate a community of STEM faculty to build Scientist Spotlight modules for many different curricular areas. This could result in a database of ready-to-use assignments matching a wide range of content areas and could additionally build a strong community of STEM educators focused on issues of equity and diversity.

\section{ACKNOWLEDGMENTS}

We extend our appreciation to Kimberly Tanner, Jennifer Myhre, the monitoring editor, and three anonymous reviewers for providing valuable feedback with regard to this article and to Jahana Kaliangara and Monica Cardenas for assisting in processing and presenting preliminary data leading up to this study. J.N.S. thanks Sonya Dreizler, Veronica Neal, Mallory Newell, IMPACT AAPI, and the Equity Action Council at De Anza College for their support. The organizers of the Conference on Understanding Interventions That Broaden Participation in Science Careers kindly provided travel funding to support our presentation of preliminary findings from this work in a lunchtime plenary in 2015. IMPACT AAPI and the Office of Staff and Organizational Development at De Anza College have generously provided J.N.S. and A.S. with travel funds to present on Scientist Spotlights at national meetings.

\section{REFERENCES}

Allen NJ, Barres BA (2009). Neuroscience: glia-more than just brain glue. Nature 457, 675-677.

Austin AE (2011). Promoting evidence-based change in undergraduate science education: a paper commissioned by the National Academies National Research Council Board on Science Education. http://sites.nationalacademies.org/cs/groups/dbassesite/documents/ webpage/dbasse_072578.pdf (accessed 9 December 2015).

Beardslee DC, O'Dowd DD (1961). The college-student image of the scientist: scientists are seen as intelligent and hard-working but also as uncultured and not interested in people. Science 133, 997-1001

Beasley MA, Fischer MJ (2012). Why they leave: the impact of stereotype threat on the attrition of women and minorities from science, math and engineering majors. Soc Psychol Educ 15, 427-448.

Begley S (2006, July 13). He, once a she, offers own view on science spat. Wall Street Journal. www.wsj.com/articles/SB1152747444775305134 (accessed 9 December 2015).

Brickhouse NW, Lowery P, Schultz K (2000). What kind of a girl does science? The construction of school science identities. J Res Sci Teach 37, 441-458.

Buck GA, Clark VLP, Leslie-Pelecky D, Lu Y, Cerda-Lizarraga P (2008). Examining the cognitive processes used by adolescent girls and women scientists in identifying science role models: a feminist approach. Sci Educ 92. 688-707.

Chamany K (2006). Science and social justice. J Coll Sci Teach 36, 54

Chamany K, Allen D, Tanner K (2008). Making biology learning relevant to students: integrating people, history, and context into college biology teaching. CBE Life Sci Educ 7, 267-278.

Cheryan S, Master A, Meltzoff AN (2015). Cultural stereotypes as gatekeepers: increasing girls' interest in computer science and engineering by diversifying stereotypes. Front Psychol 6, 49.

Cheryan S, Plaut VC, Davies PG, Steele CM (2009). Ambient belonging: how stereotypical cues impact gender participation in computer science. J Pers Soc Psychol 97, 1045

Cheryan S, Plaut VC, Handron C, Hudson L (2013). The stereotypical computer scientist: gendered media representations as a barrier to inclusion for women. Sex Roles 69, 58-71.

Cohen GL, Garcia J, Apfel N, Master A (2006). Reducing the racial achievement gap: a social-psychological intervention. Science 313, 13071310

Dee TS (2004). Teachers, race, and student achievement in a randomized experiment. Rev Econ Stat 86, 195-210

DeWitt J, Archer L, Osborne J (2013). Nerdy, brainy and normal: children's and parents' constructions of those who are highly engaged with science. Res Sci Educ 43, 1455-1476.

Ehrenberg RG, Goldhaber DD, Brewer DJ (1995). Do teachers' race, gender and ethnicity matter? Evidence from the national educational longitudinal study of 1988. Ind Labor Relat Rev 48, 547-561.

Fairlie RW, Hoffmann F, Oreopoulos P (2011). A Community College Instructor Like Me: Race and Ethnicity Interactions in the Classroom (No w17381), Cambridge, MA: National Bureau of Economic Research.

Gee JP (2000). Identity as an analytic lens for research in education. Rev Res Educ 25, 99-125.

Good C, Aronson J, Inzlicht M (2003). Improving adolescents' standardized test performance: an intervention to reduce the effects of stereotype threat. J Appl Dev Psychol 24, 645-662.

Goodenow C (1993). Classroom belonging among early adolescent students: relationships to motivation and achievement. J Early Adolesc 13 21-43.

Henderson C, Dancy MH (2007). Barriers to the use of research-based instructional strategies: the influence of both individual and situational characteristics. Phys Rev Spec Top Phys Educ Res 3, 020102.

Hill C, Corbett C, St Rose A (2010). Why So Few? Women in Science, Technology, Engineering, and Mathematics, Washington, DC: American Association of University Women.

Hunter CW (2010). Identifying barriers and bridges in developing a science identity. Doctoral Dissertation, Olympia, WA: Evergreen State College.

Inzlicht M, Ben-Zeev T (2000). A threatening intellectual environment: why females are susceptible to experiencing problem-solving deficits in the presence of males. Psychol Sci 11, 365-371.

James W (2005). The Principles of Psychology, vol. 1, South Australia: eBooks@Adelaide, University of Adelaide. http://infomotions.com/ sandbox/great-books-redux/corpus/html/principles.html (accessed 20 December 2015; original work published 1890). 
Johnson B, Christensen L (2008). Educational Research: Quantitative, Qualitative, and Mixed Approaches, Thousand Oaks, CA: Sage.

Karunanayake D, Nauta MM (2004). The relationship between race and students' identified career role models and perceived role model influence. Career Dev Q 52, 225-234.

Markus H, Nurius P (1986). Possible selves. Am Psychol 41, 954.

Martin D (2015). Women in science: are portrayals on primetime television negative, and what are effects of exposure to such content? Doctoral Dissertation, University of Missouri-Columbia.

Marx DM, Ko SJ (2012). Superstars "like" me: the effect of role model similarity on performance under threat. Eur J Soc Psychol 42, 807-812.

Marx DM, Roman JS (2002). Female role models: protecting women's math test performance. Pers Soc Psychol Bull 28, 1183-1193.

Maylor U (2009). "They do not relate to Black people like us": Black teachers as role models for Black pupils. J Educ Policy 24, 1-21.

Mclntyre RB, Lord CG, Gresky DM, Frye GDJ, Bond CF Jr (2004). A social impact trend in the effects of role models on alleviating women's mathematics stereotype threat. Curr Res Soc Psychol 10, 116-136.

Mead M, Metraux R (1957). Image of the scientist among high-school students. Science 126, 384-390.

Mills LA (2014). Possible science selves: informal learning and the career interest development process. In: 11th International Conference on Cognition and Exploratory Learning in Digital Age (CELDA) Proceedings, ed. DG Sampson, JM Spector, and P Isaias, Lisbon: International Association for Development of the Information Society, 275-279.

National Academy of Sciences (2007). Rising above the Gathering Storm: Energizing and Employing America for a Brighter Economic Future, Washington, DC: National Academies Press.

National Academy of Sciences (2011). Expanding Underrepresented Minority Participation: America's Science and Technology Talent at the Crossroads, Washington, DC: National Academies Press.

National Science Foundation (2013). Women, Minorities, and Persons with Disabilities in Science and Engineering: 2013 (Special Report NSF 13-304), Arlington, VA: National Center for Science and Engineering Statistics. www.nsf.gov/statistics/wmpd (accessed 9 December 2015).

Oyserman D, Bybee D, Terry K (2006). Possible selves and academic outcomes: how and when possible selves impel action. J Pers Soc Psychol 91, 188.

Phelan JE (2010). Increasing women's aspirations and achievement in science: the effect of role models on implicit cognitions. Doctoral Dissertation, New Brunswick, NJ: Rutgers University Graduate School.

Purdie-Vaughns V, Steele CM, Davies PG, Ditlmann R, Crosby JR (2008). Social identity contingencies: how diversity cues signal threat or safety for African Americans in mainstream institutions. J Pers Soc Psychol 94, 615.

Reece JB, Urry LA, Cain ML, Wasserman SA, Minorsky PV, Jackson RB (2014). Campbell Biology, 10th ed., San Francisco: Pearson.

Roeser RW, Midgley C, Urdan TC (1996). Perceptions of the school psychological environment and early adolescents' psychological and behavioral functioning in school: the mediating role of goals and belonging. J Educ Psychol 88, 408-422.

Schinske J, Cardenas M, Kaliangara J (2015). Uncovering scientist stereotypes and their relationships with student race and student success in a diverse, community college setting. CBE Life Sci Educ 14, ar35.

Schneider JS (2010). Impact of undergraduates' stereotypes of scientists on their intentions to pursue a career in science. Doctoral Dissertation, Raleigh: North Carolina State University. http://repository.lib.ncsu.edu/ir/ handle/1840.16/6184 (accessed 9 December 2015).

Seidel SB, Reggi AL, Schinske JN, Burrus LW, Tanner KD (2015). Beyond the biology: a systematic investigation of noncontent instructor talk in an introductory biology course. CBE Life Sci Educ 14, ar43.

Seidel SB, Tanner KD (2013). "What if students revolt?" Considering student resistance: origins, options, and opportunities for investigation. CBE Life Sci Educ 12, 586-595.

Seymour E, Hewitt NM (1997). Talking about Leaving: Why Undergraduates Leave the Sciences, Boulder, CO: Westview.

Seymour E, Wiese D, Hunter A, Daffinrud SM (2000, March). Creating a better mousetrap: on-line student assessment of their learning gains. Paper originally presented to the National Meeting of the American Chemical Society, San Francisco, March 27, 2000. http://salgsite.org/ docs/SALGPaperPresentationAtACS.pdf (accessed 20 December 2015) .

Shadish WR, Cook TD, Campbell DT (2002). Experimental and Quasi-experimental Designs for Generalized Causal Inference, Boston: Wadsworth/ Cengage Learning. http://impact.cgiar.org/pdf/147.pdf (accessed 13 December 2015).

Steele CM (1997). A threat in the air: how stereotypes shape intellectual identity and performance. Am Psychol 52, 613.

Steele CM, Aronson J (1995). Stereotype threat and the intellectual test performance of African Americans. J Pers Soc Psychol 69, 797.

Steinke J, Lapinski M, Long M, Van Der Maas C, Ryan L, Applegate B (2009). Seeing oneself as a scientist: media influences and adolescent girls' science career-possible selves. J Women Minor Sci Eng 15, 279-301.

Sue DW, Torino GC, Capodilupo CM, Rivera DP, Lin Al (2009). How white faculty perceive and react to difficult dialogues on race implications for education and training. Couns Psychol 37, 1090-1115.

Tanner KD (2009). Learning to see inequity in science. CBE Life Sci Educ 8 , 265-270.

Tanner KD (2012). Promoting student metacognition. CBE Life Sci Educ 11 113-120.

Trochim MK (2006). Quasi-experimental design. www.socialresearchmethods.net/kb/quasiexp.php (accessed 5 April 2016).

Wyer M (2003). Intending to stay: images of scientists, attitudes toward women, and gender as influences on persistence among science and engineering majors. J Women Minor Sci Eng 9(1). www.dl.begellhouse.com journals/00551c876cc2f027,588fd13a4ac98f5d,0772b1b83ebd7818 html (accessed 9 December 2015). 